\title{
Jam Sessions in Madrid's Blues Scene: Musical Experience in Hybrid Performance Models
}

\author{
Josep Pedro \\ Universidad Complutense de Madrid \\ josep.pedro.ca@gmail.com
}

\begin{abstract}
:
Examining the differences between presentational and participatory music, this paper explores the importance of jam sessions as hybrid participatory-presentational performance models and collective musical practices. As such, they display democratic and hierarchic devices that produce complex social and cultural settings, providing particular frameworks for community gathering and interaction between the different participants. Based on my field research in Madrid's blues scene, where jam sessions have proliferated widely, I will discuss two significant and distinct jams that take place every Sunday. The aim is to practically analyse what type of musical experiences and relationships they produce, considering the significance of the blues genre production and the underground status of the scene. I intend to broaden the academic interpretation of jam sessions, suggesting hybridity as a theoretical framework for analysing the social life of situated live music experiences in different genres.
\end{abstract}

Keywords: jam session, Madrid, blues, presentational, participatory, performance

\section{Introduction}

In recent years the concept of music scene has consolidated its popularity in the academic field (Bennett 2004; Bennett and Hodkinson 2012; Bennett and Peterson 2004; Shank 1994; Straw, 199), where it is used to describe "both the geographical sites of local music practice and the economic and social networks in which participants are involved" (Kruse 2010: 625). Scenes provide a flexible framework to approach contexts of music practices linked to certain territories and genres, allowing an examination of the social role of jam sessions. As collective and continuous social constructions, music scenes are dynamically shaped by the everyday practices of different participants. I am including all individuals whose actions make the reproduction of the scene possible such as professionally-oriented and amateur musicians, audience members, promoters, producers, bar owners, venues, journalists, photographers, documentarians and scholars.

There are, of course, varying levels of involvement that reveal important differences, but it is the overall collective action and, especially, the reiteration of musical practices (for example performing, listening, investing in live music or spreading cultural production) that reproduces the scene as a dynamic whole. In other words, although music scenes tend to have important leaders, the scene cannot reproduce and keep moving without the involvement of different types of participants. Musicians, audience members and producers who provide places for musical interaction constitute the minimum basic structure of a music scene.

This paper focuses on Madrid's blues scene and aims to move beyond traditional representations of jam sessions. The increasing number of jams that take place in 
Madrid, mostly dedicated to blues and other related genres like soul/funk and jazz, make the city a particularly interesting site. I have estimated that in January 2013 there were at least sixty announced jam sessions, an average of almost two per day. ${ }^{1}$ Furthermore, Madrid offers a ground-breaking site in blues studies because it addresses a blues scene in an academically unexplored context, geographically and culturally distant from where the genre originated, and different to the more frequent attention to blues traditions elsewhere in Europe, mainly Britain and France (Wynn 2007). I argue that blues jam sessions provide particular frameworks for social interaction and community gathering within the scene, where regular participants periodically share musical experiences. Gradually, attendance at jams becomes a ritual in which participants feel comfortable, developing a firm sense of belonging which is rooted both in a shared appreciation for (blues) music and in the actual experience of socializing and living a music scene.

This paper is based on a larger ethnographic field research project performed in Madrid's blues scene, which I have been conducting since September 2011. Here I rely on my personal experiences as a participant-observer and on a range of conversations and interviews with participants to approach two particular case studies through the narration of a one-day, ethnographic story. ${ }^{2}$ I emphasize the importance of present experiences in the scene - in contrast to past reminiscences - by writing in first person and in the present tense. This approach has been used by other scholars studying music scenes like Shank (1994) and Grazian (2003). The discussion begins with a brief overview of jazz literature related to jam sessions, and an introduction of some further uses of jamming in popular culture. Drawing on Thomas Turino's (2008) examination of participatory and presentational performances, and on García Canclini's (2009) definition of hybridity, I then propose to theoretically approach jam sessions as complex, hybrid performances combining participatory and presentational qualities.

After situating Madrid's blues scene as minority and underground, I introduce the two significant weekly jam sessions at Taberna Alabanda ("Alabanda Tavern") and Bodega del Águila ("Eagle Barroom") as case studies. These particular ethnographic stories examine the importance of a typical experience for regular participants by presenting a taste of the settings, social interactions and musical experiences that occur within the Sunday blues route. ${ }^{3}$ The paper concludes by confirming the hybrid nature and complexity of jam sessions as participatory-oriented events that take place in varying presentational settings. Drawing on the presented examples, I comment on their fundamental communitarian aspect and on the emergence of economic-derived problems. Ultimately, musical experiences provide a meaningful sense of belonging and an everyday site for identity construction.

\section{Jam sessions: from jazz to popular culture}

While the interest in jam sessions has not produced a unified set of studies, researchers have approached this complex phenomenon involving collective action, creative and socialization processes from different angles. In order to approach blues jam sessions, studies focused in jazz (Becker 2008; Berliner 1994; Cameron 1954; DeVeaux 1997; Pinheiro 2011) provide a useful background to understand this particular performance model, where different guest musicians take turns to perform. The interest in this area has been mainly related to learning and improvisatory processes and environments, generally seen from the musicians' point of view. At the same time, authors have implicitly and explicitly dealt with aspects of social organisation and interaction between participants around live music performances.

In his early account, Cameron (1954) defined a jam session as "a recreational rather than a vocational activity of jazz musicians." Cameron's work, based on his experience as a dance musician ("for money") and a jazz musician ("for pleasure"), set out some of the recurring ideas that have accompanied the conceptualization of jam sessions, such as the separation between "commercial" and "jazz" worlds, and between musicians and 
audiences. The author explains that "jazzmen deliberately attempt to exclude the general public from the session", and he portrays jazz musicians as social groups with peculiar norms which often lead to "some striking clashes with the conventions of the general society."

Historian Scott DeVeaux (1997: 206) revised Cameron's analysis noting that he had failed to indicate if his observations were made before or after the war and "to specify whether the musicians he studied were white or black," a crucial distinction in his view. ${ }^{4}$ More important for our purpose is DeVeaux's criticism of the recreational character attributed to jams, and of the separation of public commercial performances and afterhours jams as antagonistic situations. He argues that jam sessions were "both recreational and vocational," as the element of escape linked to nightlife, entertainment and youth was combined with a working practice where musicians could "exchange information, network with their colleagues, [and] establish a rough-and-ready hierarchy of competence" (207). Rooted in the bebop revolution of the forties (where jams have been understood as a rejection of the standardised dance environments and musical organisation of commercial swing) and its authenticity discourse, DeVeaux stresses the jam session's focus on competition within a "congenial and supportive" atmosphere, where "the ultimate purpose was to raise the quality of performance all around" (210). However, like Cameron, the author emphasizes the separation between musicians and audiences in jam sessions, as these performances "were never intended to be public spectacles" (203).

Quoting Ralph Ellison, DeVeaux refers to jams as "the jazzman's true academy" (212), a particular sphere of training where musicians learned the tradition and the necessary techniques, aspiring to develop an individual voice. Interested in improvisatory processes in jazz, Berliner (1994) also addressed jam sessions as a demanding yet liberating learning institution where students are responsible for developing as improvisers. Although Berliner argues that improvisation is rooted in a lifetime preparation that involves social practices, his underlying focus resides in improvisation from a musicological point of view. It is precisely this orientation and his exhaustive analysis of music texts that serves as a connection between jazz studies and more general performance studies. However, as Nettl (2004: 9) notes, improvisation has played a secondary role in the history of musicology, which has been more concerned with the study of finished works than with the creative process.

As the influence of jam sessions (along with improvisation and social interaction around music performance) has become important to other popular music genres, they have become not only specific performance events but also an approach to making music and a way of referring to collective celebration. In the sixties, bands like the Grateful Dead and the Allman Brothers Band (significantly rooted in blues) incorporated jamming as an improvisational practice that extended the songs through long solos and experimentation, while embodying the friendly social relationships of the psychedelic hippy era. ${ }^{5}$ Moreover, in Bob Marley's composition "Jammin"” the relationship between participants is intensified, as jammin[g] is presented as a practice involving community celebration. The song emphasizes the pleasant and liberating experience of getting together away from constrictions, and includes a collective resistance (through music) component. $^{6}$

This brief review of jam sessions and jamming in relation to different music genres (jazz, rock, reggae) raises relevant differences between the roles and the social interaction of musicians and audiences. It also speaks about the different definitions of authenticity within genre frames and about the importance of sets of shared values, depending on what participants ought to recognize in their music. For instance, jazz fans generally expect creativity and innovation onstage; rock audiences value emotional investment and purported sincerity; and reggae often relies in its own philosophy about spiritual awakening and political rebellion. As for blues, I hope this paper brings some light into the understanding of its authenticity-construction 
processes, and on how musicians in jam sessions, who vary their role (audience/musician), establish their credibility during the performance. At the same time, I stress the importance of examining the variations of jam sessions within given genres, as the particular historical contexts and places in which live music events take place affect the resulting musical experiences and social relationships around them.

\section{Jam sessions as hybrid performances}

As musicians and producers have negotiated the production of live music events, jam sessions have become common musical activities in different music scenes, and audiences have become increasingly familiar with the term and the type of musical event they should expect. In this process, jam sessions - once thought of as competitive after-hour's performances - have become open events that are announced as particular attractions of live music circuits. For this reason, I believe there is a need to update our conceptualization of jam sessions and challenge some of the prevailing assumptions. As Becker (2008: 6) reminds us, "the social systems which produce art survive in all sorts of ways, though never exactly as they have in the past." Therefore, in order to address the current spread and relevance of jam sessions as complex performance models, it is necessary to critically analyse new empirical case studies.

Introduced as particular fields involving different goals, values and practices, the concepts of participatory and presentational performances allow us to shift the analysis to different contexts such as Madrid's blues scene, considering how the orientation of music making in particular places shapes situated live music experiences and social relationships. Turino (2008: 26 ) defines participatory performance as a special type of artistic practice in which there are no artist-audience distinctions, and where the primary goal is to involve the maximum number of people in some performance role. It is about "the opportunity of connecting in special ways with others and experiencing flow" and therefore it is the "most democratic, the least formally competitive, and the least hierarchical" (35). "As such," he explains, "participatory performance does not fit well with the broader cultural values of the capitalist-cosmopolitan formation, where competition and hierarchy are prominent and profit making is often a primary goal" (35). Presentational performance, in contrast, refers to situations where "musicians must provide a performance that sustains the interest of an audience that is not participating in making the sound or dancing" (52). Meanwhile, the audience is responsible for granting attention to the performance, in varying degrees, according to the genre frame. In contrast to the emphasis on relations among participants, presentational performances show "a pronounced artist-audience separation within face-to-face situations" (51-52).

While Turino accepts that performances may combine participatory and presentational attitudes, he suggests that "one or the other orientation will ultimately emerge as more fundamental for decision making and practice" (55). However, the study of blues jam sessions in Madrid problematizes this argument, as the prevalence of one orientation is not clear. A result of a previous commercial agreement between producers and a small group of musicians that are responsible for conducting the event, jam sessions have become more presentational (because they are announced and advertised as live music events) and more participatory (because the separation between musicians and audiences has been reduced) at the same time. This starting point indicates that thinking about these performance models as a dichotomy in which one is more decisive than the other would be misleading as both are, at present, inevitably coexisting. I am therefore interested in interrogating the ways in which participatory and presentational features overlap and hybridise, and in further understanding the variety of ways in which both models are negotiated, producing different incarnations of jam sessions around blues or other styles.

I define jam sessions as hybrid performance events that, combining hierarchic and democratic devices, occur in presentational settings (musicians performing for an 
audience) within a participatory orientation (guest musicians are invited to perform). They present a participatory performance model as a means of attracting audiences (with varying levels of involvement) and guest musicians (amateur and professionallyoriented). I attempt to bring attention to the importance and potentialities of both performance models by exploring them in relation to the notion hybridity, as defined by García Canclini (2009: III): "sociocultural processes in which discrete structures or practices that existed separately are combined to generate new structures, objects and practices." Considering jam sessions as hybrid events allows us to approach the conflictual and liberating middle ground of both categories (as different yet coinciding models and sets of practices), and to examine how exactly they are combined to generate distinct, meaningful experiences in different places.

Like participatory performances, jam sessions are more about an activity involving direct social intercourse than about creating a finished product. Hence, music is more of a social process and interaction, like a ritual, or a conversation, than a textual item or object (Turino 2008: 87). As observed in Madrid, the sessions are produced without a previous programme, usually in informal environments where the musicians in charge operate on the basis of a negotiated response to the particular evolving context. The house band will start performing and then call different guest musicians (which up till then are acting as audience members), depending on who shows up. Allowing closer relationships between and among musicians and audiences than regular gigs, the participatory orientation of jams reinforces the interaction and horizontal socialization processes among scene participants. On one hand, the openness and changing dynamics of jam sessions potentially allow anyone in the audience to perform (favouring a special communication through music). At the same time, they attract groups of blues-identified non-musicians who tend to particularly value spontaneity and emotion, as well as casual bystanders who may or may not become regular participants.

Unlike Turino, who admittedly uses a restricted idea of participation - limited to the contribution to the "sound and motion of a musical event through dancing, singing, clapping and playing musical instruments when each of these activities is considered integral to the performance" (2008: 28) - I am using a wider notion of participation, which includes different roles played by for example guest musicians, audience members, photographers and bar owners. Since the kind of urban music scenes I am dealing with operate within the framework of capitalist economies, jam sessions are based on a live music economy. Therefore, in order to survive, producers need to generate monetary income for themselves and to pay musicians. In this scenario attendance at jam sessions becomes a fundamental activity in itself. Different actions like sitting in to perform, listening to the music, singing or clapping along, or buying drinks at the bar constitute different types of participation. Insofar as they contribute to the reproduction of the event in a variety of ways they should be seen as complementary, rather than opposed, actions.

As suggested previously, the production of music genres within particular scenes involves different democratic or hierarchic devices. In this regard, genres may be considered social processes that are continually constructed by musicians and audiences within the music scene (Atton 2010). A brief mention of some of blues' typical characteristics offers more insight about the democratic possibilities of blues jam sessions. First, the typical 12-bar blues form, as a repeated yet flexible melodicharmonic-rhythmic unit, offers a relatively comfortable environment to guest musicians, who do not face competition as much as amateur jazz musicians might. Furthermore, the frequent practice of various call-and-response forms (among musicians; between musicians and audiences) may "offer a small reminder that there is a democratic, communitarian moment (...) which symbolizes and anticipates (but does not guarantee) new, non-dominating social relationships" (Gilroy 1999: 79). Finally, as in participatory traditions, too much emphasis on virtuosic soloing can be 
counterproductive, especially if it overvalues an individual voice over the multiple voices within the group. In this regard, several scene musicians have talked to me about the essentially communicative dimension of music.

On the other hand, the production of jam sessions also involves scene-derived and professional hierarchies. From the musicians' point of view, there is an economic hierarchy as only a select group of musicians gets paid for performing. The process of inviting guest musicians may also involve different hierarchies depending on scene status, musical competence or personal relationships. According to these same factors, the hired musicians have either been selected by the live music producers or have successfully proposed a self-produced event to particular venues. At the same time, venues are conditioned by live music legislative frameworks. For instance, in Madrid's blues scene several jam sessions have ended after a few weeks due to problems with neighbours or live music permits. In this regard, musicians frequently refer to a repressive environment towards live music as well as to police and political harassment.

This brief overview allows us to trace a hierarchy scale. On top there is legislative framework for operation, which does not determine but seriously conditions the reproduction of music scenes. As Turley (2005: 68) summarized: "essentially, the city can pull the plug on music culture easier than almost any other type of urban culture production by denying [or gradually limiting] the zoning for music-related businesses." Then we find producers and venue owners. Production depends on their will, investment and capacity to celebrate live music events and pay musicians for their work, as well as on their decisions to end the activities. Hired musicians come next in the scale as they are the only musicians who get paid for performing in jam sessions, an activity that provides them periodic practice and monetary income. Guest musicians, whose attendance is crucial in the actual production of a jam session but do not get paid for performing, are at the bottom of this scale. Amateurs tend to play exclusively for fun and excitement; professionally-oriented guest musicians usually combine recreational motivations with the need to remain musically active and to introduce or consolidate their persona within the scene.

During the course of the investigation, I have observed rising criticism about jam sessions. In informal conversations some musicians have complained about a worrying tendency towards what they would consider an excessive number of jam sessions, particularly when several take place on a given night. One such musician, who actually conducts several weekly jams, complained about the fact that jam sessions have already become a substitute for gigs. He argued that venues invest less money in hiring bands and set up weekly open events in order to attract as many people as possible. ${ }^{7}$ Referring to both musical and economic reasons, another professional musician exclaimed that the overproduction of jam sessions is actually harming musicians: "The quality of performances is not always high, and musicians end up spending more money because they have to go to jams conducted by friend musicians or otherwise they will be shut down."

These musicians and certain live music producers who focus on gigs wish to reclaim a space in the scene for presentational music events which, they believe, should provide a monetary and performance basis for live music production. While they don't dislike participatory orientations---regular gigs in Madrid's blues scene also tend to involve guest musicians sitting in with the band---they reject an overproduction of participatory events when these involve monetary setbacks and limit gigs or band performances.

As this discussion demonstrates, jam sessions cannot be theorized exclusively as liberating or limiting practices. Rather, the hybridity of these events reflects the contradictory combination of participatory orientation within social and economic 
hierarchies. Actual lived experiences examined through these categories provide further understanding of jams within particular scenes and of genre production.

\section{Jamming in Madrid's blues scene: a taste of the Sunday blues route}

Though the origins of Madrid's blues scene date at least back to the 1960s, it was not until the 1980s that the scene emerged as an everyday collective construction involving blues musicians, producers-venues, and audiences. Since then, it has evolved into a multigenerational scene. Today there are more musicians, and there is a higher access to blues-related information. But according to accounts of veteran musicians who still remain active, the amount of venues to play at has been reduced and the laws have become more repressive and strongly enforced, making it increasingly difficult to make a living. Although the scene has expanded and provides a viable recording and live music trajectory, it has remained an underground and minority environment, providing fertile ground for intense identification. While this status involves a certain marginality, with the attendant adversities and limitations exacerbated by the current context of national economic crisis, it also gives regular participants a sense of conviction, pleasure and commitment within the symbolic and practical universe of music scenes.

I will now introduce two case studies in the form of an ethnographic stories that will take us through two jam sessions that have become increasingly popular for their friendly music environment and popular prices: the jam session at Taberna Alabanda which is organised by the Madrid Blues Society (Sociedad de Blues de Madrid, hereafter SBM) ${ }^{8}$ and conducted by different musicians each week; and the jam at Bodega del Águila, normally hosted by the blues acoustic duo Ñaco Goñi (harmonica) \& Xulián Freire (vocals, guitar). On this particular day, however, they were replaced by Duolian String Pickers (Javi Suárez: guitar, vocals; Iván 'Harpillo"': harmonica, guitar, vocals). Both jam sessions are free access and take place during daytime in unusual venues. Unlike nightclubs generally associated with live music, Taberna Alabanda and Bodega del Águila are typical local bars where one would go to have a taste of Madrid's caña y tapa ("beers and appetizers") culture.

\section{King Bee at Taberna Alabanda}

The SBM jam session at Taberna Alabanda runs approximately from 3.00 to 5.00 p.m. and has been working for almost a year, becoming one of the main meeting points for regular scene participants, as well as a frequent initial attraction for newcomers. It is located in Miguel Servet Street number 15, in Lavapiés: one of Madrid's most famous neighbourhoods, known for its multicultural environment. The bar is just a short walk away from Glorieta Embajadores, a turnaround that marks the southern limits of the city centre's district.

The tavern is a long building with an upside-down L-shape that forms two distinct rooms; the first one has the bar on the right-hand side and a row of tables where people sit down to eat on the left. In-between, customers come and go in both directions ordering beer, going out for a smoke or to keep an eye on the musicians that are playing on the stage at the end of the second room. The venue resembles a warehouse and is decorated with blues watercolour paintings by amateur artist Enrique Arranz Rámila. The music room brings together an audience combining experts and bystanders that concentrate on the live-performance. To be precise, though it is announced as a jam session, this is not a regular jam but more of a gig plus jam session or a concert-jam. It combines a strictly presentational performance and an opportunity for spontaneous participatory performance in the same event.

A different group of musicians is responsible for conducting the event each week, and for the first hour of the show these musicians play their own repertoire as in a regular gig. In the meantime, people who wish to participate in the jam sessions write 
their name and instrument down on a sheet that rests on a table at the back left corner of the room. Then things start to function like what is expected from jam sessions. Guest musicians start sitting in (replacing members of the band or contributing to larger ensembles) and after briefly negotiating the song's key and/or rhythm, the event flows spontaneously, normally for one more hour, with varying results depending on the musicians' ability and understanding.

Today the band in charge is King Bee, a quintet that gets a big part of their inspiration from Texas and Lousiana music and clearly illustrates the continuous and transnational nature of blues dialogues and connections. After being part of Madrid's blues scene for many years and gaining wider recognition with their collaborative projects (with Austin-based musician Greg Izor and his New Orleans mentor Johnny Sansone), King Bee has recently self-produced their debut album Po' Boys (2012), which can be purchased at the jam. Playing on their territorial, expressive and cultural dialogues (a Spanish band playing blues music), the album combines the title's reference to New Orleans' traditional po' boys with an appealing cover featuring the façade of a traditional Spanish bar, Freiduría de Gallinejas de Embajadores ("Embajadores Chitlins Fryer"). ${ }^{9}$

A few minutes after three, the music starts with the jazzy instrumental "Told Ya!" while I'm standing at the bar with Fran Llaguno, a frequent participant who has become a scene-friend and is buying me a beer. Though not dedicated professionally, Fran is an accomplished guitarist and singer who always enjoys playing a couple of songs at the jam. As we go in, I see Eugenio Moirón, arguably the most active member of the blues society, recording the show with his home camera. The room gets gradually packed as I recognize more representatives of the SBM: Rafaela Velasco (SBM secretary and Eugenio's wife), who acts as the regular photographer in these sessions; Jorge Biancotti, an Argentinian freelance cameraman and editor that has been involved in the scene since he moved in; and Phineas Sánchez, a professional bass player (Edu "Big Hands" \& Whiskey Train) who is a member of the board, and also joins the jam session later on.

From my previous experiences, I can recognize a variety of guest musicians among the audience. Apart from Fran, who gets on stage first, there is David Rivallo, singer and radio-program conductor; Héctor Martínez, harp player of The Forty Nighters and blues music writer; Javi Suárez, one of the younger musicians who has gained prominence in the scene; J.B. Boni, an experienced scene-guitarist; Andrea Capalbo, a young, Italian guitarist living in Madrid for a couple of years; bass player Chema Contreras; left-handed guitarist and singer Pedro Sánchez; and David Sanz, better known as El Barrendero del Blues ("The Blues Sweeper") and who actually works as a street sweeper. The show goes on and they are all called by King Bee to perform on stage a couple of selections. In the meantime, people generally listen to the music and take turns commenting on events: the songs, the changing personnel, and the Sunday blues jam experience.

Today I have invited Carmen Mateu, a long-time friend now living in Barcelona, and her friend Tomeu Antich (who are visiting Madrid for almost a week) to experience the music and the environment at the SBM jam session. Both architecture students, they appreciate different artistic expressions and, apart from visiting the celebrated museums, they are eager to listen to some live music. They are staying with Laura Ordoñez, an architecture student from Ponferrada (Castilla y León) living in Madrid that Carmen met during an exchange program in Brazil. There is also Vincent Alexandre, a French exchange program student who has moved in with Laura, and some friends of Tomeu, who don't seem to be very much into the music and leave after a few songs.

On their first visit to the SBM jam session, I recognize in Carmen and Tomeu a mix of surprise and fascination, perhaps spiced up by the pleasing feeling of discovering first-hand something new and charming. Their interest is revealed in Carmen's 
questioning about the process of how the jam actually works. Her initial insistence is on knowing more about the relationship between the performing musicians, and how much the show is improvised or previously planned. In other words, on discovering whether the exchange is actually as unrehearsed as it appears.

We are already past the usual end of the night when King Bee calls the French singer and harp player Nico Wayne Toussaint, a well-known European blues musician, up to sing. Wrapped up in his winter jacket and perfectly backed by the band, Nico performs with tremendous confidence and dedication. The remarkable rapport between the musicians gains the total attention of the audience, and as Fran and I comment on Nico's vocal style (he mentions that he draws on Junior Wells), Carmen, who feels the special value of these moments, goes to bring in her friend Laura, who has gone out for a smoke. She comes in while the band delivers a slow, gutsy blues that knocks the audience out with its staggering intensity. As Nico leaves the stage someone in the audience exclaims: "And that's without taking off his jacket!"

As always, the band in charge is responsible for closing the event, so King Bee continues with the first track of their record, the rocking "Walkin' with Frankie" (Frankie Lee Sims), which incites some easy-going dancing. The jam ends around 5.45 p.m. (nearly three hours later) while we look at each other and comment that it has been a great show.

\section{Duolian String Pickers at Bodega del Águila}

On our way out, Vincent wants to find out more about the jam process, particularly about the way in which songs are selected and performed. Happy to know that these jam sessions take place every Sunday, he also asks me about his fellow countryman Nico Wayne Toussaint, who he didn't know previously. We decide to continue the 'Sunday blues route' and take a 20-minute walk to La Latina neighbourhood till we get to Bodega del Águila, a relatively small, squareish building located at Águila Street number 14 , that stands out for its cosy environment.

Unlike Alabanda, there is no stage at this venue, and the musicians gather around some wooden stools while people sit or stand near them drinking beer and listening to the music. I explain to my companions that normally the jam is conducted by Xulián Freire and Ñaco Goñi (one of the best known harmonica players), who has been a friend of the owners for a long time. But this week they have travelled to Antequera (Málaga) to record an album for Cambayá, the main label dedicated to blues music in Spain. Instead, there's Duolian String Pickers (Javi Suárez and Iván "Harpillo"), two young players that keep a similar acoustic orientation and are earning the respect of fellow musicians, audiences and producers. As usual, the acoustic jam has two sets and runs approximately from 7.00 to 9.00 p.m.

When we arrive, Carmen immediately recognizes people who were in the previous jam. Indeed, like us, Fran, Andrea, David Rivallo, Boni, David Sanz, and Javi Suárez (who is performing) have all decided to follow the route, listen to some blues, and keep socializing throughout the Sunday afternoon. There is also Miguel Ángel, a musician and guitar luthier who has sold several vintage blues guitars to scene musicians like Xulián Freire and Javi Suárez and is a regular at these jam sessions. Again, they will all be invited and enjoy time to perform in an acoustic setting.

We stand between the door and the bar while Duolian play "Down by the Riverside", cheering the audience up. The festive atmosphere is favoured by the repertoire (rooted in country blues), the constant drinking and, particularly, by Iván's effort to engage with the audience. Apart from constantly introducing the songs along with Javi, Iván encourages an interactive relationship between guest musicians and audience members by listening and reacting attentively to their solos, and introducing them several times during their turn. Surprisingly, I also get a spontaneous chance to play guitar when, without previous notice, they call out my name. I play the standard "Rock 
Me Baby" with Javi, Iván, and 'Lauriki Blues', a young female singer. Then we play "Long Distance Call", a slow blues made famous by Muddy Waters.

While performing on an unamplified acoustic guitar, I confirm my feeling that today the environment is particularly festive because I can hardly hear the guitar when attempting to play a single-string solo. David Rivallo, who states that attending blues live music events "is a passion where we enjoy ourselves and have a good time," points out that it is the musicians' celebratory orientation that is cheering up the audience, making it more fun. Given that this is the first time I have played with Duolian String Pickers, things run relatively smoothly and I feel the excitement and satisfaction of being a guest musician. Once l'm done, I am congratulated by some of the audience members and musicians, most of who I know from the scene. Tomeu, who had previously questioned me about my performance participation in jams, congratulates me, as he reveals his surprise and joy at watching me perform. I sense there is a special value placed both by musicians and audiences on the act of performing, though the emphasis is not so much on technical musical abilities as on the contribution to this collective musical celebration.

In the break between sets, a few of us (hired musicians, guest musicians and audience members) gather outside chatting about music. Some doubts about the different ways in which harmonica can be played come up in the conversation and Iván spontaneously gives an improvised masterclass. He gets his harmonica and shows us how to produce different sounds, combining blowing, breathing in, and using the tongue. Vincent remains particularly attentive till the end of the show, when he asks the rest of us if we are going to the follow the death route attending the following jam session at La Coquette, which I had previously mentioned. But we need recuperate some energy and decide to put an end to our tour of the scene and go get something to eat.

I comfort Vincent saying that it's better not to become exhausted, because every Sunday we have the chance to come back. In the meantime, the scene keeps reproducing itself, as blues music fills the walls of La Coquette, generating new musical experiences for different participants that will continue throughout the week.

\section{Discussion}

Examined through participatory/democratic and presentational/hierarchic categories, jam sessions have revealed their hybrid nature and a set of contradictory meanings. Briefly summarized as participatory-oriented events that take place in varying presentational settings, jams are produced by collective actions where participation is fundamental, but operate in presentational settings involving varying musicianaudience separations. The way in which both orientations are combined must be examined within the continuous, situated processes of scene and genre construction. Insofar as jams sessions involve collective activities, conflicts, and negotiations, their musically-rooted complexity also speaks about general experiences of social life.

Though these examples are hardly an exhaustive or representative sample of the range of jam sessions, they do provide a window into the everyday experiences of jams as collectively-constructed live music events within Madrid's blues scene. The participatory-presentational hybridity of jam sessions is expressed differently in each of the cases I have presented. The SBM jam at Alabanda provides an example of a performance that explicitly combines a more presentational part with a more participatory one. This concert-jam format, which guarantees a certain stability and professional standard as well as some unpredictability, has given them a unique status. A different band is hired each week so there is a feeling of change---still a changing continuity---which contrasts with typical jam sessions where there is a higher repetition of musicians. Unlike all other jam sessions, the SBM jam does not provide continuous paid work to any of the scene musicians precisely because its weekly variation is 
rooted in a conciliatory orientation that aims to integrate all blues musicians into the collective scene. King Bee's drummer Carlos Arsuaga (who played uninterruptedly with different personnel for almost three hours) summarized his experience: "I had a blast and I love the environment at Alabanda, we are one big family that continues to grow".

Within its acoustic setting, and with no stage per se, the jam sessions at Bodega del Águila demonstrate the frequent blurring of lines between musicians and audiences who get together as scene participants. Musically, these jams follow a more common formula, as a 'house duo' contributes to more stable experiences. However, this particular ethnographic story precisely took place on an unusual day where, as a result of the changing dynamics of the scene, the regular duo was replaced by two upcoming musicians. That particular performance gave Duolian String Pickers the chance to start conducting their own participatory-oriented weekly jam session at Bodega del Águila which have taken place on Wednesday and, currently, on Friday nights. While the bar owners attempt to attract audiences through their live music programming, these musicians face a great opportunity and commitment to work and to get more in touch with musicians, audiences and producers, ultimately moving towards their consolidation into the blues scene.

The openness of these jam sessions is reflected both in the relationships between performing musicians (for whom they may serve as a learning institution or as a way of getting together through music making) and also in the everyday interaction of different participants that, playing out different roles, come together in the production of the scene. Actually, jam sessions can be thought of as scene reproduction mechanisms: they serve as weekly meeting points that strengthen musical and social relationships around blues, while providing work, socialization and identification contexts for participants. Blues music acts as a common anchor and tradition that has been apprehended (with similarities and differences), but there is a decisive link in experiencing a music scene through participation in the physical places where it fundamentally takes place.

\section{Conclusions}

Sunday jam sessions in Madrid's blues scene often involve a group of participants that know each other because of their common involvement in the blues scene, and gather ritually in a friendly, communal environment. At the same time, the scene regularly attracts occasional participants not only from Madrid but also from other parts of Spain and the world, who, interested in Madrid's live music culture, enjoy discovering different aspects of it. The minority and underground status of the scene, as well as its desire to grow and gain social recognition, is conducive to new relationships. Regular participants tend to interact with each other ritually in spaces where they contribute to the scene's reproduction, and new participants, who are always necessary and welcome, often bring a desirable extra element of uncertainty and excitement.

However, as I pointed out through the opinions of some informants, an overproduction of jam sessions can limit the working-gigs possibilities for musicians, thus complicating the professionalization of the blues scene. Jams do provide weekly paid performances to certain musicians, but their proliferation also acts as a competing barrier for regular presentational gigs organized by other musicians and producers, as different live blues events tend to coincide on given days. In this scenario, audiences enjoy a wide live music selection and tend to trace their own particular routes within Madrid's lively music scene.

To a certain extent, the spread of jam sessions refutes the previously presented argument that participatory events don't fit well with capitalist profit-driven economies, as jams provide profitable events and/or affordable experiments for different types of venues. However, this kind of competition is also indicative of a precarious economy, damaged by the scarce appreciation that authorities have for day-to-day live music 
interaction, and by contemporary consumerist pressures on music scene dynamics. As one of the informants (based on his experience as a jam conductor) said, jam sessions have become a "survival performance model." But they may also be interpreted as evidence of dynamism and adaptive capacities; of how individuals act collectively to overcome difficulties.

While some problems (mainly derived from economic pressure) arise in the production of jam sessions, the collective enjoyment of music-related activities within a self-conscious scene offers a positive counterbalance. The roots in genre alliances give regular participants enjoyable emotions, which tend to create a growing sense of belonging, a site for individual and collective identity construction, and a narrative line in their life stories.

\section{Endnotes}

${ }^{1}$ I have considered the thirty-eight jam sessions announced at the SBM (Madrid Blues Society) calendar, as well as the twelve jams which took place at El Plaza Jazz Club, five at Tempo Club, four at Marula Café and one at El Intruso Bar.

${ }^{2}$ I use the term ethnographic story to describe the particular form of written products of field research activity. Case studies, which here I understand as the study of specific places or venues where jam sessions are performed, produce different ethnographic stories depending on the varying circumstances of field immersions (date, participants involved, repertoire, etc.).

${ }^{3}$ Ironically referred to as the death route by some participants, the complete Sunday blues route starts around 3.00 p.m. at Taberna Alabanda, and is followed by the jam sessions at Bodega del Águila (7.00 to 9.00 p.m.) and at La Coquette (9.00p.m.- ). This ethnographic story refers to the experiences at Taberna Alabanda and Bodega del Águila on 3 February 2013. Being a recent date, it speaks (to a certain extent) about the current situation of the scene. Furthermore, I was joined by some visiting friends, which gave me additional insights on how these jam sessions are experienced by regular and occasional participants.

${ }^{4}$ DeVeaux (1997: 207) argues that "white musicians were far more likely to take on the role of "jazzmen as romantic outsiders"' and that for black musicians "the music profession offered one of the few consistent means of social advancement".

5 The Allman Brothers 19-minute interpretation of "You Don't Love Me" in Live at Fillmore East (Capricorn 1971) provides a clear example: http://www.youtube.com/watch?v=0wsUNMSilll

${ }^{6}$ Although the whole text is significant, this orientation is demonstrated in verses like: "Ain't no rules, ain't no vow, we can do it anyhow" / "No bullet can stop us now, we neither beg nor we won't bow, neither can be bought nor sold" / "True love that now exists is the love I can't resist, oh jam by my side".

${ }^{7}$ As a norm, clubs pay musicians a smaller amount of money for leading jam sessions than for conducting a regular gig. In other words, club owners need less money to produce jam sessions, which involve guest musicians that do not get paid, than to hire a band to play a regular concert. This can be a double-edged sword. On one hand, it may be conducive to more live music events. On the other, it may serve as a comfortable formula following the principle of cost minimization.

${ }^{8}$ The SBM was presented on 29 February, 2012. Driven by the effort of local blues enthusiasts, it has now become the main organization in the scene. http://www.sociedaddebluesdemadrid.com 
${ }^{9}$ Gallinejas ("chitlins") is a traditional dish prepared out of chicken or lamb intestines, which provided cheap meals for the working class. Freiduria de Gallinejas de Embajadores is one of the few places that still prepares them.

\section{References}

\section{Bibliography}

Atton, C. (2010) Popular Music Fanzines: Genre, Aesthetics, and the 'Democratic Conversation'. Popular Music and Society, 33 (4): 517-531. http://dx.doi.org/10.1080/03007761003694316

Becker, H. (2008) Art Worlds. Berkeley, Los Angeles and London: University of California Press.

Bennett, A. (2004) Consolidating the music scenes perspective. Science Direct https://www.sfu.ca/cmns/courses/2011/488/1Readings/Bennett\%20Consolidating\%20Music\%20Schenes.pdf Accessed: 19 Feb 2013.

Bennett, A. and Hodkinson, P., Ed (2012) Ageing and Youth Cultures. Music, Style and Identity. London and New York: Berg.

Bennett, A. and Peterson, R. Ed (2004) Music Scenes. Local, Translocal, and Virtual. Nashville: Vanderbilt University Press.

Berliner, P. (1994) Thinking in Jazz. The Infinite Art of Improvisation. Chicago and London: University of Chicago Press.

Cameron, W. (1954) Sociological Notes on the Jam Session. Connection.ebscohost.com http://connection.ebscohost.com/c/articles/13517771/sociological-notes-jam-session Accessed: 19 Feb 2013.

DeVeaux, S. (1997) The Birth of Bebop. A Social and Musical History. Berkeley, Los Angeles, London: University of California Press.

Faulkner, R., and Becker, H. (2009) "Do you know...?" The Jazz Repertoire in Action. Chicago and London: The University of Chicago Press.

García Canclini, N. (2009) Culturas Híbridas. Estrategias para entrar y salir de la modernidad. México y Colombia: Randon House Mondadori.

Gilroy, P. (1999) The Black Atlantic. Modernity and Double Consciousness. London and New York: Verso.

Grazian, D. (2003) Blue Chicago. The Search for Authenticity. Chicago: University of Chicago Press.

Kruse, H. (2010) Local Identity and Independent Music Scenes, Online and Off. Popular Music and Society, 33 (5): 625-639. http://dx.doi.org/10.1080/03007760903302145

Nettl, B. and Russell, M. Ed. (2004) En el transcurso de la interpretación. Estudios sobre el mundo de la improvisación musical. Madrid: Akal.

Pinheiro, R. (2011) The Creative Process in the Context of Jazz Jam Sessions. Journal of Music and Dance, 1 (1): 1-5. Academicjournals.org http://www.academicjournals.org/JMD/PDF/Pdf2011/January/Pinheiro.pdf Accessed: 19 Feb 2013.

Shank, B. (1994) Dissonant Identities: The Rock ' $n$ ' Roll Scene in Austin, Texas. New England: Wesleyan University Press.

Straw, W. (1991) Systems of articulation logics of change: communities and scenes in popular music. Straw Research 
http://strawresearch.mcgill.ca/straw/systemsofarticulation.pdf Accessed: 19 Feb 2013.

Turino, T. (2008) Music as Social Life. The Politics of Participation. Chicago: The University of Chicago Press.

Turley, A. (2005) Urban Culture. Exploring Cities and Cultures. New Jersey: Pearson Prentice Hall.

Wynn, N. Ed (2007) In Cross Water Blues. African American Music in Europe. Jackson: University Press of Mississippi. 